\title{
Design and Experimental Study of Solar Hybrid Bicycle: A Review
}

\author{
H. S. Upare, P. S. Pandure \\ (Department Of Mechanical Engineering, M. E. S. College Of Engineering, S.P. Pune Unuversity-411001, \\ India)
}

\begin{abstract}
In present scenario a Solar Hybrid Bicycle system will help to solve the major problems of fuel and pollution. There is no doubt that the emission of carbon-dioxide from an automobile exhaust is a concern for the increasing rate of global warming. The fuel prices in India and around the world is increasing day by day thus there is a tremendous need to search for an alternative to conserve these natural resources. Promoting use of hybrid vehicles can reduce $\mathrm{CO}_{2}$ emission and the fuel costs. Thus a solar bicycle is an electric vehicle which provides alternative by utilising solar energy to charge the battery and thus provide required voltage to run the motor. India is blessed with nine months of sunny climate thus concept of solar bicycle will be very useful in India. Hybrid bicycle combines the use of solar energy as well as the dynamo that runs through pedal to charge the battery to run the bicycle. The bicycle has the most feasible solar/electric power generation system mounted on the vehicle to charge the battery during all durations. This multi charging vehicle can charge itselffrom both solar and mechanical power. Solar panels can be mounted on the backside of bicycle to capture the sun rays. When there is no presence of sun, mechanical work act as an auxiliary energy source. For controlling speed of the motor, an accelerator is given which controls the supply. This type of technique is to reduce the running cost and increasing the running efficiency of the vehicle. The speed of the Solar Hybrid Bicycle can go up to 25-30 $\mathrm{km} / \mathrm{hr}$ carrying a load of a person of average weight. Thus solar hybrid bicycle can become a vital and cheap alternative against the use of automobile and thus its manufacturing is essential. The aim of present study is to learn about different types of energy used to run a bicycle and try to find some new idea in improving the solar hybrid bicycle.
\end{abstract}

Keywords: Alternative, Bicycle, Energy, Hybrid, Solar.

\section{Introduction}

In this various aspects, types and different techniques are studied and analysed to get a better understanding of the bicycle running on hybrid energy. In this paper, the method used to transform one form of energy into another is studied. The use of solar, mechanical and electrical energy to drive the bicycle is discussed. The components used in the manufacturing and the cost related to it is also studied. The use of power generated through solar panels can also be used for other purposes. Types of solar panels used are monocrystalline, polycrystalline and amorphous panels. Different panels have varying range of efficiency and they are used according to their applications [1]. There are different types of batteries used in electric vehicles like lead acid batteries, lithium ion batteries, Nickel cadmium batteries, etc. Different batteries have advantages for different applications. A sample model is also shown to get a better understanding of the design of the bicycle, so that any kind of development in the design can be suggested for further improvement. A motor is used to drive the bicycle, it depends on the power generated by the hybrid system. The motor can be mounted on the front wheel or the rear wheel. Different types of solar cells are used for different application depending upon the price, material and efficiency. The method to generate power using pedalling is suggested so that it uses hybrid form of energy. Application of this bicycle is suggested and the improvement in the efficiency of the battery is discussed [2].

\section{Design Of Solar Hybrid Bicycle}

Mishra et al. [3] have designed and developed the solar hybrid bicycle. Author have completely designed every part required in the making of the bicycle. In this research paper, even the CAD model of the bicycle have been shown Fig.1. The lead acid battery is used for storage of energy, since it is cheap, easily available and also it is explosion free. A hub motor is used, which is a conventional type of DC motor. The stator is inside the rotor, the stator is fixed on the axle and the rotor is made to rotate by AC supplied by the battery. This motor provides high torque, is efficient and dispels the need of sprockets, brackets and drive 
chains. Solar energy is directly converted to electrical energy using photovoltaic cells which work on photoelectric effect. It also gives an alternative method to charge the battery using pedalling. A permanent magnet alternator is used to convert mechanical to electrical energy as shown in Fig. 2. It generates alternating current which charges the battery. In this way, the solar hybrid bicycle is designed for carrying a load of $70 \mathrm{~kg}$ person, at $15 \mathrm{kmph}$.

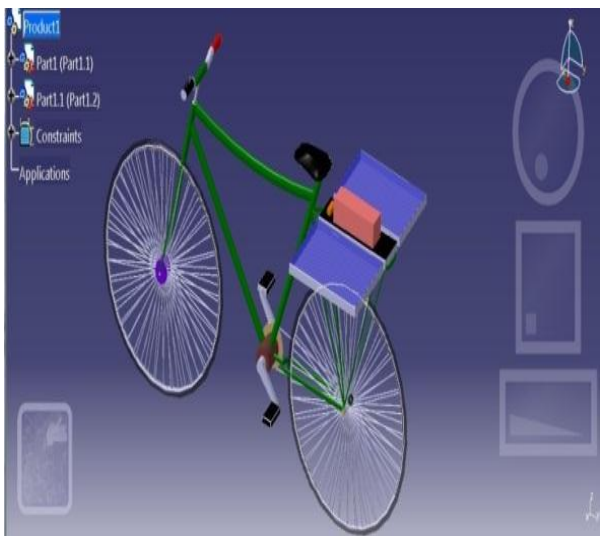

Fig. 1 CAD model of solar bicycle

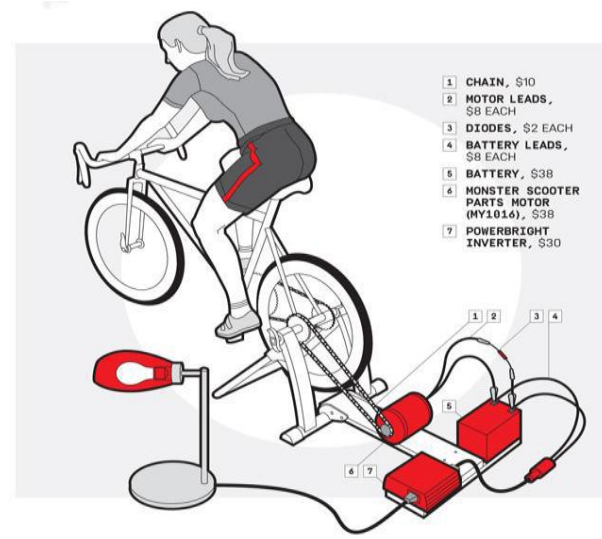

Fig. 2 Electricity generation from pedalling

M R Sankar et al. [2] studied the solar assisted bicycle developed is driven by DC motor which is mounted on front or rear wheel and operated by solar energy. The solar panels mounted on the carriage will charge the battery \& which in turn drive the hub motor. When the bicycle is idle, the solar panel will charge the battery. This arrangement can replace the petrol engine, the gear box and the fuel tank in case of a two wheeler. As a part of dissertation work, the solar assisted bicycle is fitted with a dc hub motor on front axle of a bicycle with power rating of $250 \mathrm{~W}$ and with a travelling speed of around $25-30 \mathrm{kmph}$. It is provided with a pair of lead acid batteries of $35 \mathrm{Ah}$ each, a photovoltaic solar panel with capacity of 20 watt, a voltage regulator of $24 \mathrm{v} 10$ Amp, accelerator and motor controller of $24 \mathrm{v} 25 \mathrm{Amp}$. There is also a provision for charging of the battery with $220-240 \mathrm{~V}$, AC wall outlet supply, in case of poor solar supply due to cloudy weather. A throttle allows to drive the motor from zero speed to full speed. The throttle is fitted on right side of the handle bar and is connected to controller. The throttle converts DC voltage from battery to an alternating voltage with variable amplitude and frequency that drives the hub motor at different speeds. It consists of MOSFET transistors and a small microprocessor.

\section{Types Of Solar Cells}

Sharma et al. [3] have studied different types of solar panels and its application. In study, different solar cells and their efficiency is discussed as shown in Fig. 3. The evolution of solar cells beginning from 1\% efficiency to $22 \%$ efficiency is shown. The first generation cells were the wafer based silicon cells, they are of two type's mono and multi crystalline silicon cells. Then came the thin film solar cells, it consists of a-Si, CdTe and CIGS (copper indium gallium di-selenide). Their efficiency ranges from $4 \%-12 \%$ depending upon the type. The next type are the nano crystal based, polymer based, dye sensitized and concentrated type of solar cells. They are less commercially used but their efficiency is about $8 \%-10 \%$. The last type studied is perovskite based solar cell on which lot of research is going on, it is a halogen based cell with an expected efficiency of $31 \%$.Technology based on nano-crystal QD of semiconductors based solar cell can theoretically convert more than sixty percent of the whole solar spectrum into electric power. The polymer base solar cells are also a viable option. The author concluded that there is a need of further innovation in this technology since the material used degrades in due course of time and due this efficiency decreases. 


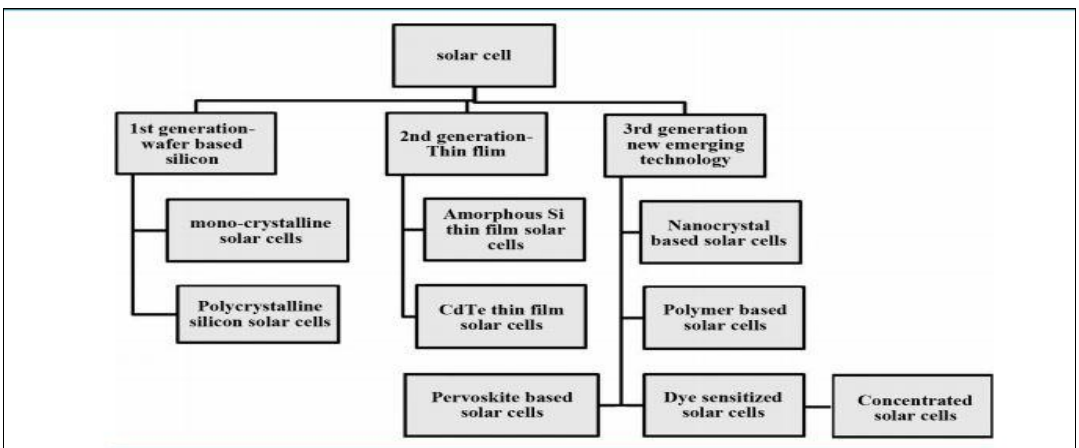

Fig. 3 Types of Solar cells

Sethi et al. [4] have studied the use of nanotechnology in solar cells. The method to implement nano crystals in solar cells for better performance and efficiency is proposed. The manufacturing cost of these cells is less than the conventional silicon cells or the thin film based amorphous Si cells. The film coating is in nanometres therefore the material used is less, this type has three main advantages. Firstly, multiple reflections take place due to which there is more absorption of energy. Second, electrons emitted need to travel less and recombination losses are reduced. Third, energy band gap can be altered as per use. The use of semiconductor Quantum Dots (QD) and carbon nano tubes for collection of electrons to generate electrical current. Different size of layers and different luminescent $\mathrm{Si}$ were used for maximising absorption of energy bands of different wavelengths. A company has propose to generate power at 30 cents per watt using this technique. The application of nanotechnology to benefit rural people and provide electricity for various purpose is given.

\section{Pedal Power Generation}

R K Megalingam et al. [5] has presented a way to charge the batteries or use the power generated by the pedalling of a bicycle. The importance is given mainly to the use of dynamo or the alternator as per the power required. Dynamo or an alternator is used to convert the rotational energy of the wheel into electrical energy. An overview of the energy generated and where it ca be used is shown. At first NiCd (Nickel Cadmium), batteries were used but later were changed to NiMH (Nickel Metal Hydride) since it had added advantages. A dynamo produces less power around $3 \mathrm{~W}$ compared to an alternator which produces power in the range of $50 \mathrm{~W}$ to $100 \mathrm{~W}$ depending on the rate of pedalling. It is found that alternator though it takes more space and is heavy but it is capable of generating more energy than the dynamo. Energy loss cannot be avoided and is present in each stage, from production to storage. Energy loss happens in the battery, in the alternator/dynamo, in the converter (which converts ac to dc), in the voltage regulator. Various household appliances can be charged using this technique, blenders can be directly connected to the wheel for use without the need of battery, laptops, mobiles, and washing machine can be run at expense of human work. Hsieh and Jair. [6] has designed a 300W energy generator using a bicycle or HPEG (Human Power Energy Generator). The output power of the developed HPEG system had the maximum output power $300 \mathrm{~W}$ at the rotation speed of $790 \mathrm{rpm}$. In this study, axial flux permanent magnet (AFPM) is used for HPEG to generate electricity. The HPEG system is mounted on the rear wheel and the battery is placed on the carrier of the bicycle. Results were found by placing the bicycle in different conditions like on training stand, uphill and downhill at different speeds. Driving at higher speeds will give higher output power. For downhill travel at normal speed of 500rpm (60 kmph) 215W was generated. For this purpose a lithium battery is used since it is light weight and gives long duration power. A battery of $36 \mathrm{~V}$ and $9 \mathrm{Ah}$ is used alongwith a brushless DC motor of $350 \mathrm{~W}$ as shown in Fig. 4 


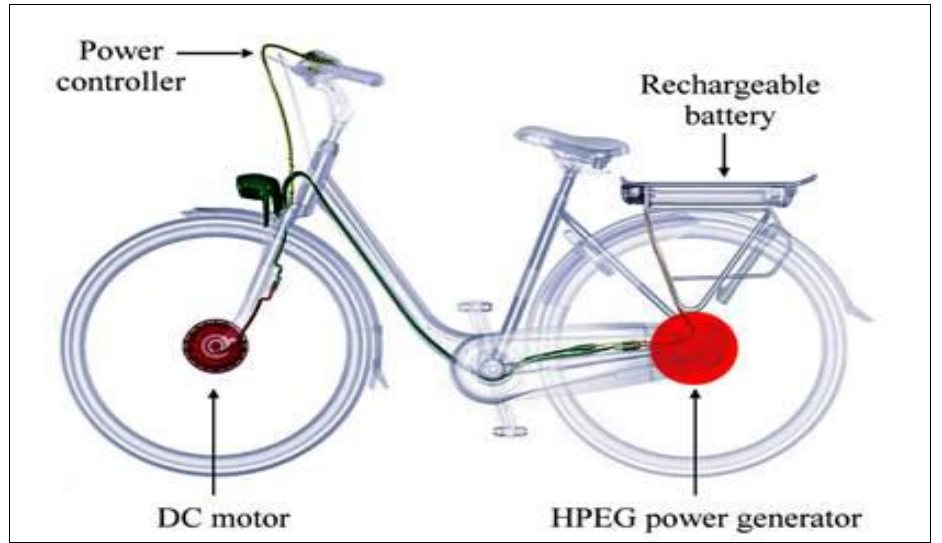

Fig. 4 Power generation by pedalling

Experiments showed that $300 \mathrm{~W}$ power was generated at $790 \mathrm{rpm}$ and $100 \mathrm{~W}$ at $25-30 \mathrm{kmph}$ during normal road test. The graph of output voltage (Fig. 5) and current vs rpm (Fig. 6) shows that the voltage and current increases as the rpm of the pedalling increases. The current increases rapidly and then it gradually increases. Similarly the output power also increases and maximum of $300 \mathrm{w}$ is achieved at $790 \mathrm{rpm}$.

B Sneha and Dr M D Reddy [7] have proposed to generate electricity and directly use it for devices without the need of storing ii in batteries. The block diagram and circuits applied in it are shown. The rotation of the wheel is provided to the generator having permanent magnet where voltage is generated. Voltage produced is unregulated dc which is provided to LM317 circuit to give regulated $12 \mathrm{v}$ dc as shown in Fig. 7.

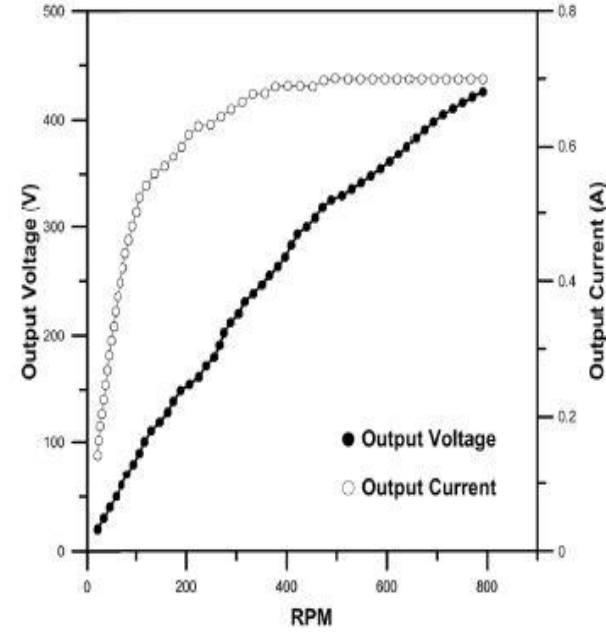

Fig. 5 Output Voltage V/S RPM

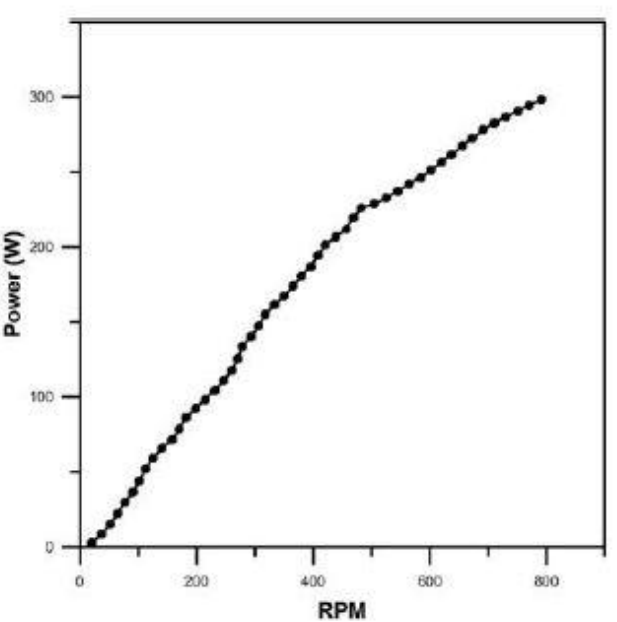

Fig. 6 Output Power V/S RPM

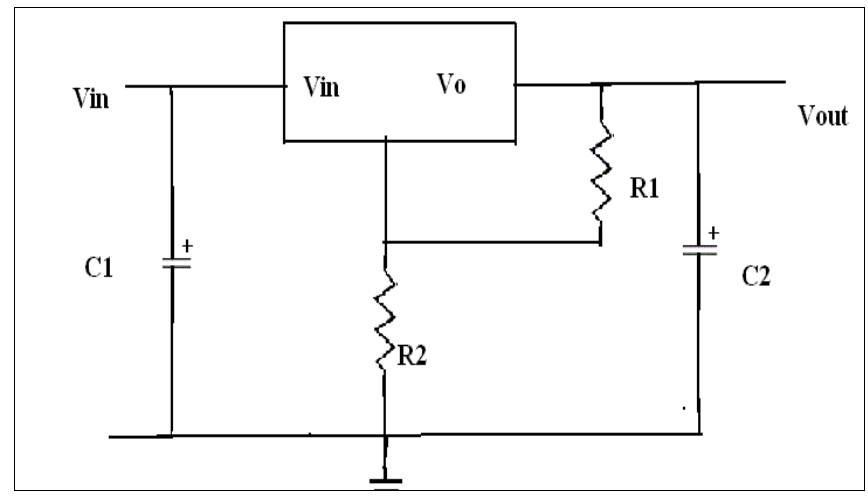

Fig. 7 LM317 Charger circuit model 
This $12 \mathrm{v} \mathrm{dc}$ is given to the inverter to convert it to $230 \mathrm{v}$ ac. The inverter model used is KA3525A, this is directly provided to the load for further use. Some hardware results were given of the model for general idea. The maximum voltage produced was $37 \mathrm{v}$ at $5000 \mathrm{rpm}$ and maximum current being $2.2 \mathrm{~A}$ at same rpm. Their findings showed that an average human being can generate $75 \mathrm{~W}$ of power which can be very useful.

Table 1

\begin{tabular}{|c|c|}
\hline $\begin{array}{c}\text { RPMS OF } \\
\text { ROTOR }\end{array}$ & VOLTAGE \\
\hline 1000 & 9.1 \\
\hline 1500 & 14.2 \\
\hline 2500 & 17 \\
\hline 3200 & 23.5 \\
\hline 5000 & 37 \\
\hline
\end{tabular}

The Table 1 shows voltage increases as the rpm increases and voltage is in dc regulated form. The maximum voltage is $37 \mathrm{~V}$ obtained at $5000 \mathrm{rpm}$ of rotor due to pedalling.

\section{Conclusion}

After studying various research papers, the following conclusions are proposed.

- The solar hybrid bicycle can be a very good application of renewable energy which will reduce pollution and can be useful device for villagers, where the provision of electricity is not adequate.

- This can be used even in the absence of sunlight since it has an alternate source of power generation.

- Though the efficiency of solar cells is very low and it is also a costly device it has capability to sustain longer. It is a combination of both, non-polluting and an equipment of maintaining health.

- Many research is going on increasing the efficiency of solar cell with reduction in use of material thus making it a cheaper and cleaner form of energy.

\section{References}

[1]. S. Sharma, K. Kumar Jain and A. Sharma,"Solar Cells: In Research and Applications-A Review”, Materials Sciences and Applications,vol. 6, 2015, pp. 1145-1155.

[2]. M. R. Sankar, T. Pushpaveni and V. B. Reddy, "Design and Development of Solar assisted bicycle", International Journal of Scientific and Research Publications, Volume 3( 3),2013, pp. 452-457, ISSN 2250-3153.

[3]. Kartik S Mishra*, Shubham V Gadhawe, Dhiraj C Chaudhari, BhupendraVarma and S. B. Barve, "Design and Development of Solar Hybrid Bicycle”, International Journal of Current Engineering and Technology, pp. 378-380, ISSN $2277-4106$.

[4]. V.K.Sethi, M. Pandey and P. Shukla, "Use of Nanotechnology in Solar PV Cell”, International Journal of Chemical Engineering and Applications, Vol. 2(2),2011, pp. 77-80, ISSN: 2010-0221.

[5]. R. K. Megalingam, P. S. Veliyara, R. M. Prabhu, R. Katoch, "Pedal Power Generation", International Journal of Applied Engineering Research, ,Vol.7(11),2012, pp., ISSN 0973-4562.

[6]. M. C. Hsieh and D. K. Jair," Design and Realization of a 300 W Human Power Energy Generator System on a Bicycle", Energy and Environment Research; Vol. 4(2); 2014,pp.73-89, ISSN 1927-0569.

[7]. B.Sneha and .M. D. Reddy, "Generation of Power from Bicycle Pedal", International Journal of Advanced Research in Electrical, Electronics and Instrumentation Engineering, Vol. 4(10), pp. 8429-8434, 2015, ISSN:2278 - 8875. 